\title{
Dependence of the wetting rate of the loess base on the moisture conditions
}

\author{
Rustam Xujakulov ${ }^{1 *}, U$ Normurodov $^{2}, M$ Zaripov $^{1}, U$ Abdurakhmonov ${ }^{1}$, and Mustafo \\ Berdiev $^{3}$ \\ ${ }^{1}$ Karshi Engineering and Economic Institute, Kashkadarya, Uzbekistan \\ ${ }^{2}$ Bukhara Branch of Tashkent Institute of Irrigation and Agricultural Mechanization Engineers, \\ Bukhara, Uzbekistan \\ ${ }^{3}$ Tashkent Institute of Irrigation and Agricultural Mechanization Engineers, Tashkent, Uzbekistan
}

\begin{abstract}
The increasing demand for improved irrigation systems in the world requires a more comprehensive and widespread study of the reliability and safety of hydraulic structures. In this regard, increasing the reliability during the operation of hydraulic structures of irrigation systems, especially on collapsible soils, is very important because loess subsidence soils are widespread globally, a significant part of loess rocks are also found in Central Asia, including the Republic of Uzbekistan. This article discusses the study of the features of the joint work of full-scale irrigation structures with their loess subsidence bases and the intense - deformative state of subsidence foundations during their joint work with hydraulic structures on irrigation canals of the Kashkadarya region.
\end{abstract}

\section{Introduction}

The practice of irrigation development of loess lands shows that the disturbances in the operation of hydraulic structures that have occurred so far are due to insufficient knowledge and neglect in designing the features of joint work and interaction of structures with their subsidence bases. The design of hydraulic structures also does not fully take into account these features.

To ensure long-term, reliable, and economical operation of hydraulic structures on collapsible soils, it is necessary to improve their design and construction methods, taking into account the peculiarities of interaction with loess bases.

The experiments were preceded by the development of a methodology, their thorough preparation, the choice of methods for processing the results obtained following the recommendations of N.N. Frolov [3], S.V. Zasov [11].

The process of filtration moistening of soils, including subsidence soils, has been studied by many authors: M.A. Bandurin [2], A.M. Budikova [3], O.N. Chernykh [3], S.N. Belyakova [4], A.V. Varyvdin [5], A.G. Vasilevsky [6], A.B. Veksler [7], D.A. Ivashchintsev, D.V. Stefanishin [7], V.A. Volosukhin [8], M.R. Bakiev [1].

As shown earlier in the analysis of the works of several scientists A. Dzhumanazarova

*Corresponding author: rustam868793@mail.ru 
[9], D.V. Dokin, R. Xujakulov [21], S.V. Zasov [11], B.D. Kaufman [12], Yu.M. Kosichenko [13], F.V. Matveenkov [14], V.M. Fedorov [24], O.R. Krupnov, D.Bazarov [22] failure to take into account the anisotropy of the properties of wetted collapsible soils, as well as the formation of two layers with different physical and mechanical properties in them leads to a discrepancy between the calculated and actual values of the subsidence of loess soil, R. Xujakulov [20-30], [25], M. Zaripov, E. Nabiev [19-21].

\section{Methods}

In the course of the stamping tests of loess subsidence soils carried out in the zone of irrigation systems, simulating the operation of hydraulic structures, the dependence of the nature of the process of moistening on the conditions of soaking the soil mass was studied.

In the course of the experiments, it was found that if a stamp serving as a model of the GTS flatbed transmits to the ground a pressure greater than the initial subsidence pressure, then the rate of advance of the wetting front into the soil mass and the outlines of the moisture zone are different than at a pressure lower than the initial subsidence pressure. Immediately under the stamp, the wetting rate is, in this case, less than slightly away from it. This can be explained by the deformations occurring in the core under the stamp, which result in a decrease in porosity and a decrease in the filtration capacity of the soil. In addition, the load transmitted by the stamp to the soil affects the horizontal dimensions of the wetted part of the soil massif, which largely determine the nature of the deformation of the subsidence of loess soils.

\section{Results and Discussion}

If the area of the pit is large enough, then when the stamp transfers pressure $\mathrm{P}>\mathrm{P}$, the filtration flows passing outside the deformable zone on the sides of the stamp, as it were, flow around it over time, which contributes to a more intensive increase in the depth of moisture outside the core. As can be seen from Figure 1, when moistening the bases of round dies with an area of $1 \mathrm{~m}^{2}$ located in the center of the pit $\mathrm{D}=5 \mathrm{~m}, 24$ hours after the start of soaking, the depth of the moistened zone under the center of the punch, which transfers a load of $0.2 \mathrm{MPa}$ to the ground, is $60 \mathrm{~cm}$ less than under an unloaded stamp.

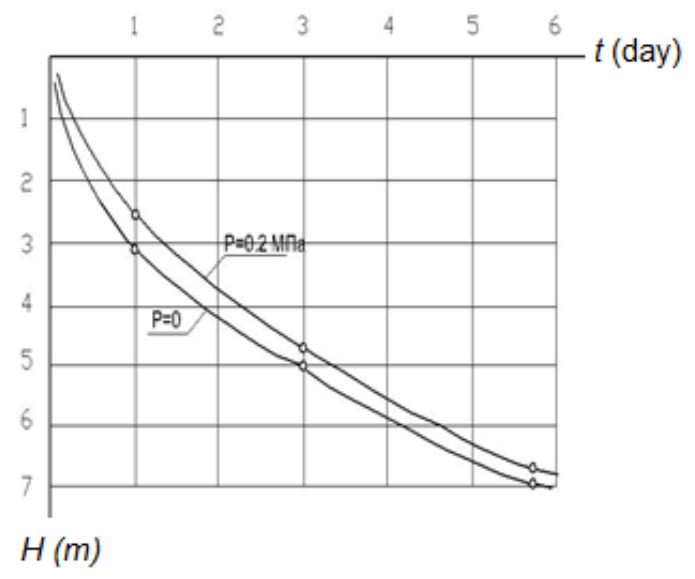

Fig. 1. The graph of the change in the depth of the wetted zone under the center of a circular stamp with an area of $1 \mathrm{~m} 2$ installed in the pit $\mathrm{D}=5 \mathrm{~m}$. Distributor area 4 . 
However, after 6 days of soaking, this difference will stop insignificant. In this case, the front of soil moistening is at a depth of more than 6 meters.

A different picture is observed when the bases of the stamps are soaked through small pits. In such experiments, the most dramatic slowdown in the process of movement of the wetting front into the depth of the massif was observed with an increase in the pressure transmitted by the stamp to the ground.

Figure 2 shows the graphs of the dependence of the depth of the moistening zone of subsidence foundations with a round stamp with an area of $1 \mathrm{~m}^{2}$ transmitting various pressures to the bases when they are moistened through pits with an area of $1,23 \mathrm{~m}^{2}$ on the time of soaking. As can be seen from the figure, the pressure on the depth of the wetted zone becomes more significant with time. The soil cushion formed due to loading, which has a low filtration capacity, causes the accelerated formation of a stabilized suspended contour of the humidification zone.

Thus, the deformed zone in the soaked loess base of the loaded punch has a reduced filtration capacity and affects the nature of the soil moistening process.

Studies have shown that the rate of advance of the front moistened in the loess subsidence foundation is the greater, the greater the volume of water supplied to the pit and the area of the pit through which soaking is carried out, and the less, the larger the area of the foundation and the pressure transferred by this foundation to the ground.

Often, in cases where the calculation of relationships between any parameters causes certain difficulties, researchers also resort to using diagrams, which are one of the simple and visual methods for graphically describing (modeling) the process under study. They make it possible, without complex calculations, by simple geometric constructions to reveal a complex relationship between several parameters.

For any three parameters under consideration, with a constant fourth, a flat diagram can be constructed. Such a diagram does not allow identifying the relationship between the four variables. However, this relationship can be clearly shown in a 3-D chart. So, based on experimental data, it is possible to construct a volumetric diagram for the soaking depth of the subsidence base of the structure, depending on the size of the water source and foundation, the time of soaking, and the magnitude of the pressure transmitted by the foundation to the ground.

Figure 3 shows a diagram showing the dependence of the depth of the wetting zone of loess foundations on time at pressure from the foundation on the ground, $P=0.05 \mathrm{MPa}$ for various ratios $F_{K} / F_{f}$,

where $F_{K}$ is the area of the pit through which the base of the stamp is soaked,

$F_{f}$ is area of the stamp (foundation)

Using this diagram, it is possible, given the ratio $\mathrm{F}_{\mathrm{K}} / \mathrm{F}_{\mathrm{f}}$, for which there is a curve, and the soaking time, to determine the depth of soil wetting.

If the value $\mathrm{F}_{\mathrm{K}} / \mathrm{F}_{\mathrm{f}}$ differs from the values for which the experimental data are available, then it can be determined by the interpolation method. So for point $b$, the parameters were obtained, where $\mathrm{t}=144$ hours, $\mathrm{F}_{\mathrm{K}} / \mathrm{F}_{\mathrm{f}}=15, \mathrm{H}_{3}=6 \mathrm{~m}$.

A similar diagram can be constructed for any three of the considered parameters $\left(\mathrm{F}_{\mathrm{K}} / \mathrm{F}_{\mathrm{f}}\right.$; t, P, H3) with a constant fourth. A flat plot does not allow establishing a relationship between four variables. This relationship can be clearly shown in a 3-D chart. 


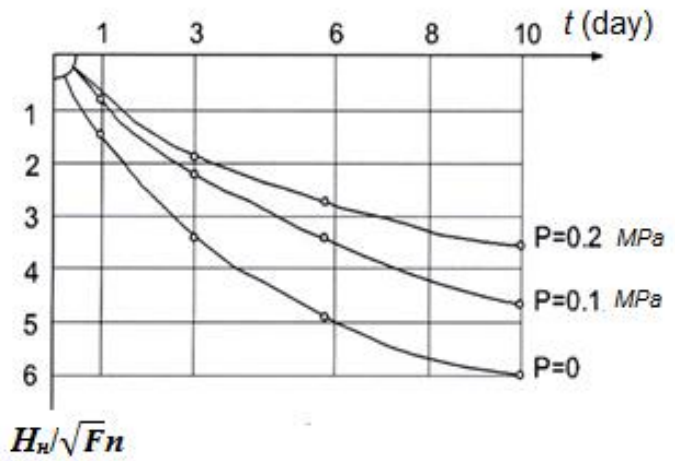

Fig. 2. The depth of the wetted zone of the loess bases of the dies (circle, $F=1 \mathrm{~m}^{2}$ ) as a function of the soak time. Pit area $1.23 \mathrm{~m}^{2}$

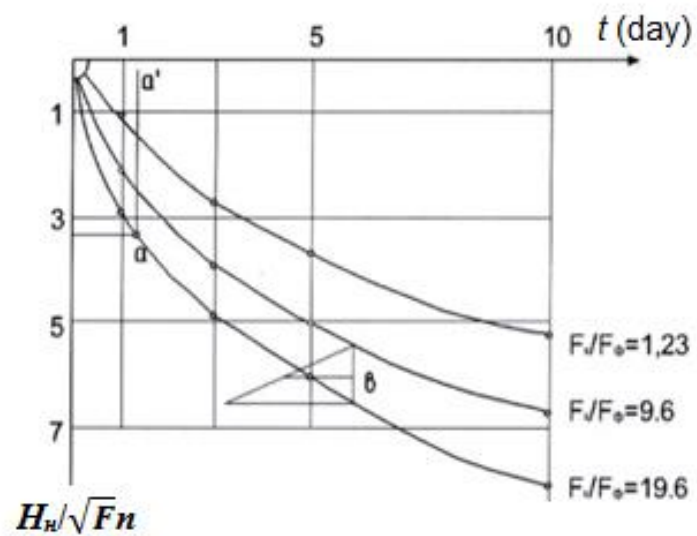

Fig. 3. The depth of the wetted zone of the loess bases of the dies (circle with an area of $1 \mathrm{~m}^{2}$ ) as a function of time. Pressure at the contact of the stamp and the ground $\mathrm{P}=.05 \mathrm{MPa}$

Figure 4 shows a three-dimensional diagram showing the mutual dependence of three variables $\left(\mathrm{F}_{\mathrm{K}} / \mathrm{F}_{\mathrm{f}} ; \mathrm{t} ; \mathrm{H} 3\right)$ at different values of $\mathrm{P}$. In this case, each accepted experimental value of $\mathrm{P}$ corresponds to a plane on which the soaking time curves are given in the coordinates $\mathrm{F}_{\mathrm{K}} / \mathrm{F}_{\mathrm{f}}$ and $\mathrm{H} 3 \ldots$ The diagram is based on the results of stamp tests of soils in the distributor zone 4-X. The image of the plane I, II, III, IV, V for the values of P equal to 0 , respectively; $0.05 ; 0.10 ; 0.15 ; 0.020 \mathrm{MPa}$. This diagram consists of five diagrams like the previous one. It is visual and allows you to solve a wider range of problems due to a wide range of changes in the parameters under consideration and the ability to interpolate their values.

The presence of several planes in the diagram in Fig. 4 makes it possible to determine any of the four considered quantities not only at the values of $\mathrm{P}$, for which these planes are plotted according to the experimental data but also at its intermediate values, using the interpolation method.

For example, let us determine the depth of the moistened zone of the base of the stamp transmitting pressure to the ground $\mathrm{P}=0.12 \mathrm{MPa} 72$ hours after the start of soaking at $\mathrm{F}_{\mathrm{K}} / \mathrm{F}_{\mathrm{f}}$ $=6$. To solve this problem, it is necessary to determine the position of the point on an imaginary plane corresponding to $\mathrm{P}=0.12 \mathrm{MPa}$ at given values, and $\mathrm{F}_{\mathrm{K}} / \mathrm{F}_{\mathrm{f}}$.

To do this, postponing the values of $\mathrm{P}$ and $\mathrm{F}_{\mathrm{K}} / \mathrm{F}_{\mathrm{f}}$ along the $\mathrm{x}$ and $\mathrm{y}$ axes, respectively, we determine the position of point $\mathrm{A}^{\prime}$, which is a secondary projection of the desired point $\mathrm{A}$. To find the point itself, you need to transfer the line of the secondary projection (a space of 
the diagram taking into account the given time $t=72$ hours. In this case, with an error insignificant for practical purposes, the line ab can be considered a segment of a straight line. The segment $\mathrm{AA}^{\prime}$ expresses on the scale of the drawing the value of the depth of the wetted soil zone H3. In our case, it is obtained equal to $3.1 \mathrm{~m}$.

Suppose the specified value of $t$ does not coincide with the values for which the corresponding curves are drawn within the displayed planes. In that case, it can also be found by interpolation between adjacent curves.

The volumetric diagram makes it possible to clearly demonstrate the influence of such factors as the ratio of the areas of the pit and the foundation, as well as the pressure transmitted to the ground by the foundation, on the rate of advance of the front moistened into the depth of the soil mass.

However, the forecast obtained using the proposed diagram will be valid only when the soil conditions of the object under consideration are similar to those of the experimental site.

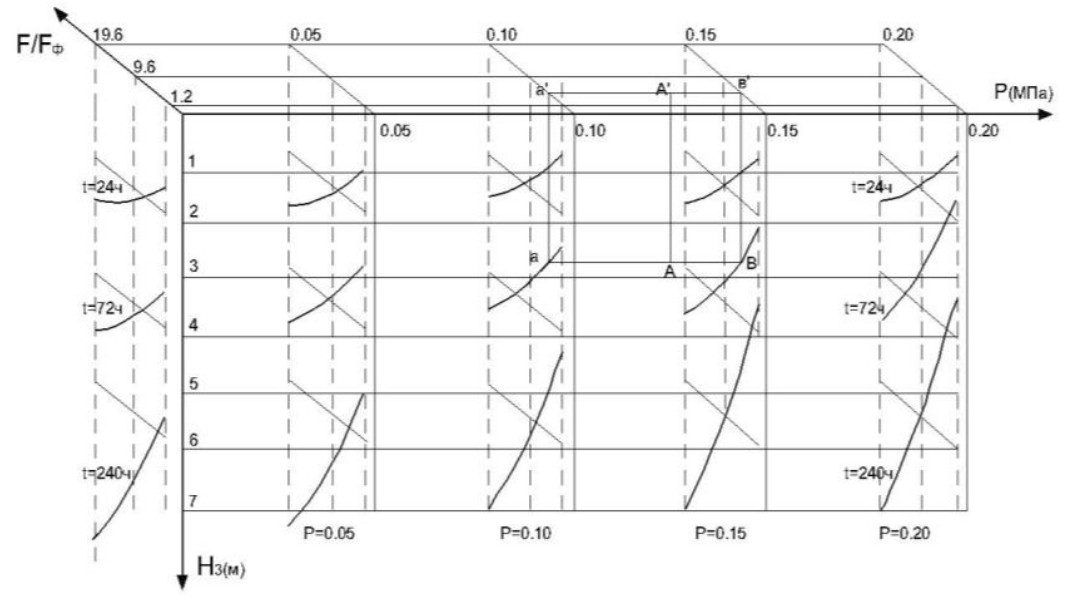

Fig. 4. Volumetric diagram of the wetting process of loess bases of round dies with an area of $1 \mathrm{~m}^{2}$ (distributor 4) Depth of the wetting zone of loess bases of dies (circle with an area of $1 \mathrm{~m}^{2}$ ) as a function of time. Pressure at the contact of the stamp and the ground $\mathrm{P}=0.05 \mathrm{MPa}$

An illustration of this is the diagram shown in Figure 5, similar to the previous one, obtained from the results of experiments carried out in the area of the distributor 2-X massif Abdulla Kodiriy Karshi steppe.

By comparing the diagram, one can make sure that the rate of advance of the moistening front of the soil mass in the area of the $2-\mathrm{X}$ distributor is $10-16 \%$ lower than in the area of the 4-X distributor. This indicator is valid for cases with similar experimental conditions, regardless of the size of the pit and the pressure transmitted by the stamp to the ground. The foregoing makes it possible to use the proposed diagrams in predicting the time of soaking of loess collapsible soils with other physical and mechanical characteristics. To do this, it is necessary to find out the ratio of the rates of soaking of the investigated and "reference" massifs by setting up one or several experiments in the area under consideration. A soil massif for which there is already a diagram of a similar type should be taken as a reference.

At the same time, it must be admitted that carrying out stamp tests, even in limited quantities, requires considerable effort and time.

In the course of experimental work in the zone of the distributor 4-X massif "Turkmenistan", we investigated the process of wetting the massif of soil both through the above-mentioned round and through rectangular pits, which simulate canal sections and have dimensions (in meters) of $0.5 \times 0.5 ; 0.5 \times 2.5 ; 0.5 \times 5 ; 1,1 \times 1,1 ; 1,1 \times 2,2 ; 1,1 \times 5,5 ; 1$, 
$1 \times 11 ; 2.0 \times 2.0 ; 2, \times 6,0 ; 2.0 \times 12.0$. The depth of filling the pit with water was $0.4-0.5 \mathrm{~m}$. The obtained data were compared with the results of a study of the process of wetting the foundations of canals built on the same soil area and having a width of $0.5 ; 12 ; 2.0$ meters.

From the graphs in Fig. 6, constructed according to experimental data, it can be seen that with an increase in the length 1 of the pit, the rate of advancement of the moistening front into the depth of the soil massif also increases. However, there is no direct proportionality between these values. The rate of advance of the humidification front at $\mathrm{B}=$ const also tends to its limit if $1 \rightarrow \infty$.

Figure 7 shows graphs characterizing the growth of the depth of the soaked part of the soil massif $\mathrm{H} 3$ with an increase in the area of the pit through which the soaking $\mathrm{H}^{\prime} 3 / \mathrm{H} 3=\mathrm{f}$ (F2 /F1) for time $\mathrm{t}=10$ days is given after the start of soaking. Curve 1 was obtained by comparing the values of $\mathrm{H} 3$ when the soil was moistened through compact (round or square in plan) pits of different areas, and the second curve was obtained by comparing the results of soaking rectangular pits having the same width $\mathrm{B}$ but different lengths 1 and compact pits with area $\mathrm{F}=\mathrm{B}^{2}$. In the region $\mathrm{H}^{\prime} 3 / \mathrm{H} 3$, covered by the experiments, the positions of the points are described by the expression $y=a e^{b x}+c$, where the coefficients found by the least squares method, with the natural passage of the curves through the point, are $\mathrm{a}=8.65^{*} 10$; $\mathrm{b}$ $=4.79 ; \mathrm{c}=10$ with a correlation coefficient of 0.825 (for the first curve) and $\mathrm{a}=2.28^{*} 10^{-3}$; $\mathrm{h}=26.81 ; \mathrm{c}=0,9$ (for the second curve). The standard deviation for these curves is, respectively, \pm 0.1 and \pm 0.035 .

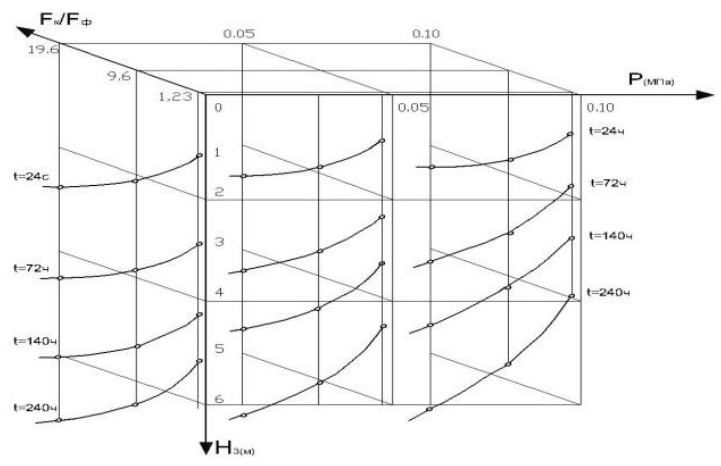

Fig. 5. Diagram of the process of moistening loess soils, 2-way distributor

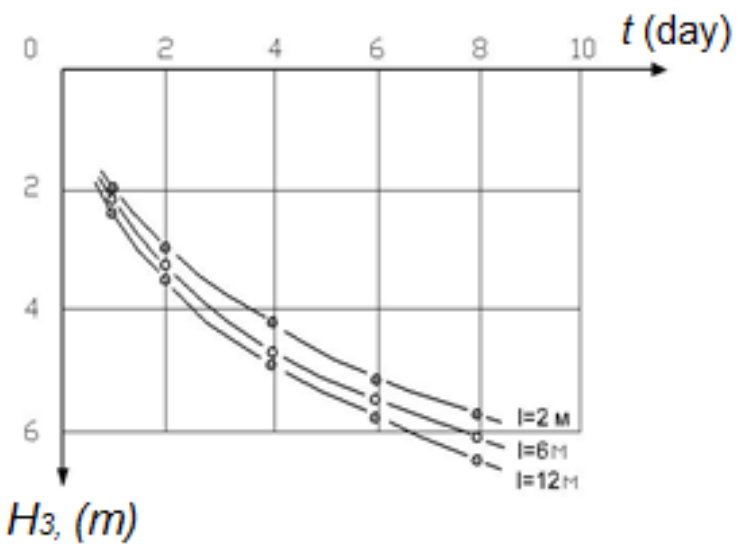

Fig. 6. Graphs of changes in the depth of the wetted zone under the pits, having a width of $2 \mathrm{~m}$. 


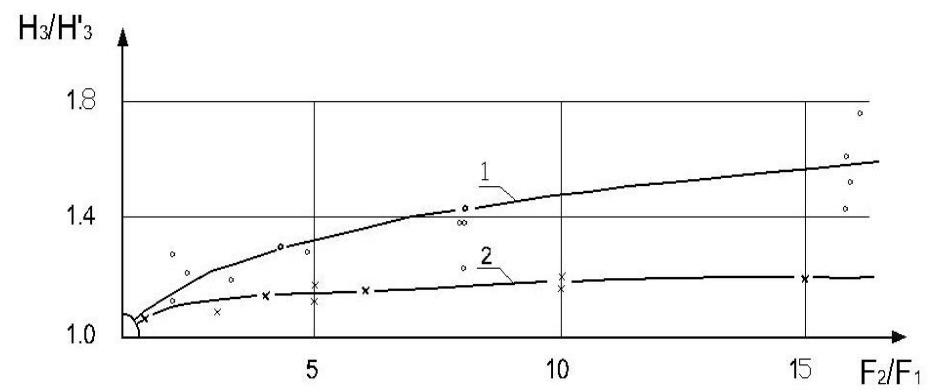

Fig. 7. The graph of the growth of the depth of the wetted part of the soil massif with increasing area of foundation pits: 1 is compact pit; 2 is rectangular pit

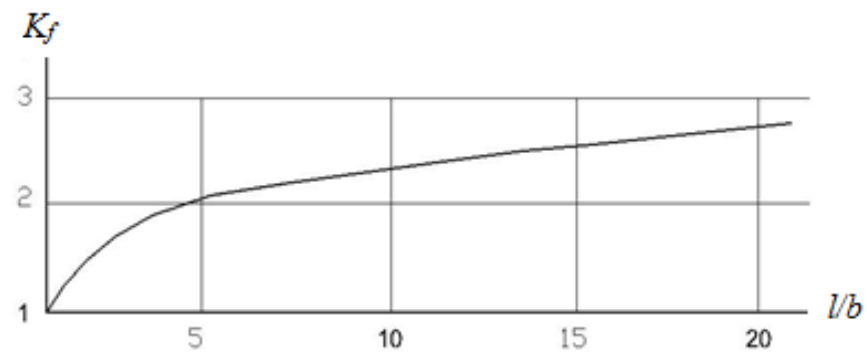

Fig. 8. The graph of the dependence of the coefficient of reduction of the shape of the pit on the relationship of its dimensions in the plan

From the graphs shown in Figure 7, it can be seen that an increase in the area of a square pit due to the length of the parallel sides in the plan by a factor of 8,2 gives the same increase in the rate of wetting the massif of loess soil, as an increase in the area of a compact pit by 2, 2 times, provided that its shape. Using such a comparison, the graph is shown in Figure 8.

Based on the above graph, we can conclude that the rate of advancement of the moistening front in the loess base of a rectangular pit with dimensions $\mathrm{B} \times \mathrm{x}$ is equal to the velocity in the same base of a compact pit with an area $F_{K}=K_{f} F_{l}$,

where $K_{f}$ is the coefficient of reduction of the pit shape is taken from the graph in Figure 8 and takes into account the change in the length 1 of the water source (takes into account the equivalence of the soaking rate)

$$
F_{1}=B^{2}
$$

For channels, the Kf values should be taken within the range of $2,9 \div 3,0$. Such a ghost of the dimensions of a rectangular pit makes it possible to use diagrams of type 1.4 and 1.5 in calculating the time of soaking a mass of loess soil.

\section{Conclusions}

The device used in this work, proposed by the authors of [13] for studying the physical and mechanical properties of soil, creates additional possibilities for studying the process of moistening loess soils.

An experimental-graphical method for determining the rate of soaking of an array of loess foundations of canals and structures on them has been developed, making it possible to determine the optimal sizes of pits intended for preliminary soaking of the foundations of 
hydraulic structures.

The volumetric diagrams of the loess soil moistening process proposed in work clearly demonstrate that the rate of advancement of the moistening front into the depth of the base of the stamp (foundation) decreases with an increase in the soaking time, the pressure transmitted by the stamp (foundation) to the soil and the area of this stamp, and increases with an increase in the intensity of moistening and the area of the water mirror in the pit through which the soaking is carried out.

\section{References}

1 Bakiev M.R. Criteria for the reliability of the Ugam irrigation system, International scientific and practical conference, Improving the efficiency, reliability and safety of hydraulic structures, 1, pp. 23-28, (2018)

2 Bandurin M.A. Diagnostics of the technical state and assessment of the residual service Life of water-supplying structures of irrigation systems, Moscow, MGUP, p. 285 (2017)

3 Budikova A.M., Frolov N.N., Chernykh O.N. To the question of the reliability of the foundations of reclamation structures on subsiding soils, Sat. materials of the AllRussian Scientific and technical conference, pp. 147-148, Moscow, (2003)

4 Belyakova S.N. Justification of technical solutions to ensure the operational reliability of hydrotechnical structures in St. Petersburg. Author's abstract for the co-academic degree of candidate of technical sciences, St. Petersburg, p. 16, (2007)

5 Varyvdin A.V. Determination of the reliability of hydraulic structures and their elements, Collection of materials of the All-Russian Scientific and technical conference, pp. 135-137, Moscow, (2003)

6 Vasilevsky A.G. World experience in the development of hydropower, engineering solutions in the field of dam building and ensuring the safety of hydraulic structures. OJSC VNIIG. g.Hydrotechnical construction, 4. pp. 49-55, (2003)

7 Veksler A.B., Ivashchintsev D.A., Stefanishin D.V. Reliability, social and environmental safety of hydraulic facilities: risk assessment and decision-making. St. Petersburg: OJSC "VNIIG" named after B.E. Vedeneev. pp. 156-159, (2002)

8 Volosukhin V.A. Factors determining the safety of hydraulic structures for water management purposes, Science and security, 3 (12), pp. 7-8, (2014)

9 Dzhumanazarova A. Studies to determine the final value of subsidence of the foundatio of hydraulic structures Agricultural technologies, 1(4), pp.10-15, Russian Federation, (2019)

10 Dokin D.V. Determination of the size of the zone of subsidence deformations in foundations composed of loess subsidence soils, Materials of the VIII regional scientific and technical conference SevKav GTU, Stavropol. pp. 37-41, (2004)

11 Zasov S.V., Khuzhakulov R. Improving the operational reliability and safety of hydraulic structures of irrigation systems on subsidence soils, Tashkent, p. 162, (2019)

12 Kaufman B.D. Assessment of the reliability of hydraulic structures under dynamic influences under conditions of the incompleteness of the initial information, Saint Petersburg, p. 35 (2015)

13 Kosichenko Yu.M. Issues of safety and operational reliability of hydraulic structures for reclamation purposes, Nature improvement, 3, pp. 67-71, (2008)

14 Matveenkov F.V. Development of measures to improve the operational reliability of soil hydraulic structures of III and IV classes, p.20, Moscow, (2016)

15 Krutov, A., Norkulov, B., Nurmatov, P., Mirzaev, M. Applicability of zerodimensional equations to forecast nonconservative components concentration in water bodies, 883(1), 2020, doi:10.1088/1757-899x/883/1/012064 
16 Robert F. Dam safety: the use of guidance documents for the training of inspector engineers Hydraulic construction, 4(2003), pp. 43-49,

17 Rustam Xujakulov, Musliddin Zaripov. Research on determination of the structures, In JournalNX-Multidisciplinary Peer Reviewed Journal - Special Issue on "Application of Science for Sustainable Development to Overcome Covid-19 Pandemic" (2020)

18 Khidirov S., Norkulov B., Ishankulov Z., Nurmatov P., Gayur A. Linked pools ulverts facilities. IOP Conference Series: Materials Science and Engineering. 883,(1) pp. (2020), doi:10.1088/1757-899x/883/1/012004

19 Bazarov D., Markova I., Norkulov B., Isabaev K. Operational efficiency of water damless intake, (2020), doi:10.1088/1757-899X/869/7/072051

20 Xujakulov R. Rahmatov M., Nabiev E., and Zaripov M. Determination of calculating stresses on the depth of loess grounds of hydraulic structures, IOP Conf. Series: Materials Science and Engineering 1030 (2021) doi:10.1088/1757899X/1030/1/0121331 (2021)

21 Bazarov D., Vatin N., Obidov B., and Vokhidov O. Hydrodynamic effects of the flow on the slab of the stand in the presence of cavitation, IOP Conf. Ser. Mater. Sci. Eng. 1030,012110 (2021)

22 Xujakulov R. Stresses in subsidence bases of flutbet models under the moisturizing conditions, IOP Conf. Series: Materials Science and Engineering 1030 (2021), IOP Publishing doi:10.1088/1757-899X/1030/1/012138 1

23 Sozaev A.A. General characteristics of the state of trough canals of the Chegem irrigation and watering system: a collection of articles of the RIO DSTU.-NalchikMakhachkala, pp. 273-275, (2007)

24 Fedorov V.M. The complex of constructive and technological means of restoring and I ncreasing the reliability of the water supply network of irrigation systems, Novocherkassk, p. 48, (2012)

25 Xujakulov R. Establishment of the degree of moisture and stress values when determining the magnitude of the subsidence of the foundations of hydraulic structures, International Scientific and Technical Conference, National Technical University "Dnipro Polytechnic" (Ukraine), pp. 138-140, (2019)

26. Bazarov D., and Vokhidov O. Extinguishing Excess Flow Energy in Spillway Structures, In book: Proceedings of EECE 2020, LNCE 150, pp. 535-545, (2021) DOI: 10.1007/978-3-030-72404-7_52

27. Obidov B., Vokhidov O., Tadjieva D., Kurbanova, U., Isakov A. Hydrodynamic effects on the flow elements of the downstream devices in the presence of cavitation, IOP Conf. Ser. Mater. Sci. Eng. 1030, 012114 (2021)

28. Matyakubov B., Begmatov I., Raimova I. and Teplova G. Factors for the efficient use of water distribution facilities, IOP Conf. Ser. Mater. Sci. Eng. 883, 012025 (2020)

29. Uralov B., Rakhmatov N., Khidirov S., Uljaev F., Raimova I. Hydraulic modes of damless water intake, IOP Conf. Ser. Mater. Sci. Eng. 1030(1), 012123 (2021)

30. Bazarov D., Norkulov B., Vokhidov O., Uljaev F., Ishankulov, Z. Two-dimensional flow movement in the area of protective regulatory structures. IOP Conf. Ser. Mater. Sci. Eng. 890, 012162 (2020) 